\title{
Designer's Note
}

You may have noticed that Policy Perspectives looks a little different this year. We've redesigned the look of the journal and reduced the size of the book to make the content more accessible.

But more important than the look of Policy Perspectives is how we've changed the process of printing it. In redesigning the journal, we wanted to better reflect our mission, and the university's goal, of strong environmental leadership. We at Policy Perspectives are extremely proud of University President Stephen Knapp's recent efforts. But we also know that it's everybody's job to figure out how to reduce our individual, and the University's, carbon footprints.

So I'm pleased to announce that the journal you now hold in your hands is truly "green":

- Wéve used 100 percent post-consumer recycled paper, so no trees were sacrificed to bring you this edition. I like to think we harvested last year's term papers instead. This requires less than half the energy of virgin paper, and reduces landfill waste and methane emissions, which are more than ten times more potent than carbon dioxide.

- The paper is Certified Processed Chlorine Free (PCF), sparing us of the noxious chemicals released by the tradition bleaching process.

- The entire printing process was powered with renewable energy, saving the emissions created from fossil fuel power plants.

- Lastly, wére using soy-based inks. Petroleum-based inks emit three times the smog-creating, hazardous-to-your-health volatile organic compounds (VOCs). Soy-based inks require less than one percent of the total energy needed for traditional inks and are biodegradable.

That's the nitty-gritty of the new Policy Perspectives. I hope you enjoyed our fifteenth edition, both for the probing content inside these pages, and the light environmental footprint of the pages themselves.

\section{Lisa Pettibone}

Design Coordinator 